\title{
An audit of influenza vaccination status in adults with inflammatory bowel disease
}

\author{
Neeraj Narula MD, Amit S Dhillon MBBS, Usha Chauhan RN MN, John K Marshall MD MSc FRCPC AGAF
}

\begin{abstract}
N Narula, AS Dhillon, U Chauhan, JK Marshall. An audit of influenza vaccination status in adults with inflammatory bowel disease. Can J Gastroenterol 2012;26(9):593-596.
\end{abstract}

BACKGROUND: Several guidelines recommend influenza vaccination for high-risk patients, including those on immune-suppressing medications (IS).

OBJECTIVE: To assess the vaccination status and immunization history of an outpatient inflammatory bowel disease (IBD) population for H1N1 and seasonal influenza.

RESULTS: Among 250 patients, 104 (41.6\%) had been immunized against $\mathrm{H} 1 \mathrm{~N} 1$ and 62 (24.8\%) against seasonal influenza, and $158(63.2 \%)$ were taking IS (azathioprine, 6-mercaptopurine, infliximab, adalimumab, methotrexate, cyclosporine or prednisone). Among subjects on IS, the presence of comorbidities warranting vaccination was associated with higher likelihood of H1N1 immunization $(62.5 \%$ versus $35.8 \% ; \mathrm{P}=0.022$ ) but not of seasonal influenza vaccination ( $25.0 \%$ versus $17.2 \% ; \mathrm{P}=0.392$ ). Among patients without comorbidities warranting vaccination, IS was associated with a decreased likelihood of vaccination against seasonal influenza (17.2\% versus $30.7 \%$; $\mathrm{P}=0.036$ ) but not $\mathrm{H} 1 \mathrm{~N} 1$ ( $35.8 \%$ versus $41.3 \%$; $\mathrm{P}=0.46$ ). The frequency of $\mathrm{H} 1 \mathrm{~N} 1$ vaccination was significantly higher among patients who visited a general practitioner at least once yearly (45.7\% versus $20 \% ; \mathrm{P}=0.0027)$, with a similar trend for seasonal influenza vaccination $(27.1 \%$ versus $12.5 \% ; \mathrm{P}=0.073)$. Among 91 patients on IS who declined vaccination, $39.6 \%$ reported fear of immediate side effects, $29.7 \%$ reported concerns about developing serious medical complications, $15.4 \%$ reported concerns about activating IBD and $15.4 \%$ were not aware that vaccination was indicated.

CONCLUSIONS: Current strategies for vaccinating IBD patients on IS are inadequate. Primary care provider education, incentive programs and regular primary care contact may improve immunization uptake.

Key Words: Crohn disease; Immunization; Influenza; Inflammatory bowel disease; Ulcerative colitis; Vaccination

Influenza infection is responsible for significant morbidity and mortality in epidemic years (1). Patients undergoing immunosuppressive therapies are considered to be more susceptible to influenza infection and its complications (2). Although most individuals recover from influenza infection, adults and children with chronic illnesses, such as inflammatory bowel disease (IBD), are at greater risk for poor outcomes such as pneumonia and death (3). Infections, including influenza, may also exacerbate IBD (4).

Influenza is one of many vaccine-preventable illnesses in adults and children (5). Annual vaccination of immune-suppressed patients has been recommended by several agencies including the Public Health Agency of Canada (2,5-7). Furthermore, recent guidelines from the European Crohn's and Colitis Organization recommend routine influenza vaccination of all IBD patients, irrespective of therapy (8). Influenza vaccination is safe and immunogenic in patients with IBD using immune-suppressing medications (IS) (9). Despite this, influenza vaccination uptake has previously been noted to be as low as $24 \%$ among IBD patients, the majority of whom reported current or

\author{
Une vérification du statut de vaccination contre \\ l'influenza chez les adultes atteints d'une maladie \\ inflammatoire de l'intestin
}

HISTORIQUE : Dans plusieurs lignes directrices, on recommande la
vaccination contre l'influenza aux patients à haut risque, y compris ceux qui prennent des immunosuppresseurs (IS).

OBJECTIF : Évaluer le statut de vaccination et les antécédents de vaccination d'une population ambulatoire ayant une maladie inflammatoire de l'intestin (MII) à l'égard de la grippe H1N1 et de l'influenza saisonnière.

RÉSULTATS : Chez les 250 patients, 104 (41,6\%) avaient été vaccinés contre la grippe H1N1 et $62(24,8 \%)$ contre l'influenza saisonnière, et $158(63,2 \%)$ d'entre eux prenaient des IS (azathioprine, 6-mercaptopurine, infliximab, adalimumab, méthotrexate, cyclosporine ou prednisone). Chez les sujets qui prenaient des IS, la présence de comorbidités justifiant la vaccination s'associait à une plus forte probabilité de vaccination contre la grippe $\mathrm{H} 1 \mathrm{~N} 1$ (62,5\% par rapport 35,8 \%; $\mathrm{P}=0,022)$, mais pas de vaccination contre l'influenza saisonnière (25,0\% par rapport à $17,2 \%$; $\mathrm{P}=0,392)$. Chez les patients sans comorbidités justifiant la vaccination, les IS s'associaient à une diminution de la probabilité de vaccination contre l'influenza saisonnière $(17,2 \%$ par rapport à $30,7 \% ; \mathrm{P}=0,036)$ mais pas contre la grippe H1N1 (35,8\% par rapport à 41,3\%; P=0,46). La fréquence de vaccination contre la grippe H1N1 était considérablement plus élevée chez les patients qui avaient rendez-vous avec un praticien généraliste au moins une fois l'an (45,7\% par rapport à $20 \% ; \mathrm{P}=0,0027)$. On remarquait une tendance similaire à l'égard du vaccin saisonnier contre l'influenza (27,1\% par rapport à $12,5 \% ; \mathrm{P}=0,073)$. Chez les 91 patients qui prenaient des IS et ont refusé la vaccination, 39,6\% ont déclaré la crainte d'effets secondaires immédiats, $29,7 \%$ se sont dits inquiets de présenter de graves complications médicales et 15,4\%, d'activer leur MII, tandis que $15,4 \%$ ne savaient pas que la vaccination était indiquée.

CONCLUSIONS : Les stratégies actuelles pour vacciner les patients atteints d'une MII qui prennent des IS ne sont pas adaptées. La formation des dispensateurs de soins de première ligne, des programmes incitatifs et des contacts réguliers avec les soins de première ligne peuvent accroître les taux de vaccination.

previous use of IS (10). To explore influencing factors, an audit of immunization status for both H1N1 and seasonal influenza was undertaken among IBD patients attending outpatient gastroenterology clinics at a Canadian university hospital.

\section{METHODS}

A total of 250 consecutive adult patients ( $\geq 17$ years of age) with IBD attending the McMaster University Medical Centre Digestive Disease Clinic (Hamilton, Ontario) were enrolled between May and August 2010. No exclusion criteria were specified. A two-page questionnaire was used to gather information regarding age, sex, diagnosis, comorbidities, current treatment, vaccination status (including receipt of H1N1 influenza and/or seasonal influenza in the preceding 12 months), sources of counsel regarding vaccination and underlying motive for vaccine refusal, if applicable. No patient refused to participate. The research was approved by the McMaster University/Hamilton Health Sciences Research Ethics Board.

Department of Medicine, Division of Gastroenterology, and Farncombe Family Digestive Health Research Institute, McMaster University, Hamilton, Ontario Correspondence: Dr John K Marshall, Division of Gastroenterology (2F59), McMaster University Medical Centre, 1280 Main Street West, Hamilton,

Ontario L8S 4K1. Telephone 905-521-2100 ext 76782, fax 905-523-6048, e-mail marshllj@mcmaster.ca

Received for publication April 22, 2011. Accepted December 29, 2011 
TABLE 1

Characteristics of the sample population

\begin{tabular}{lc}
\hline Demographics & \\
Patients, $\mathrm{n}$ & 250 \\
Age range, years (median) & $17-86(36)$ \\
Female sex & $153(61.2)$ \\
Diagnosis & \\
Crohn disease & $177(70.8)$ \\
Ulcerative colitis & $70(28.0)$ \\
Indeterminate colitis & $3(1.2)$ \\
Immunosuppressive therapy & \\
Yes & $158(63.2)$ \\
No & $92(36.8)$ \\
\hline
\end{tabular}

Data presented as $n$ (\%) unless otherwise indicated

TABLE 2

H1N1 and seasonal influenza vaccination profile of sample population

\begin{tabular}{|c|c|c|c|}
\hline & \multirow[b]{2}{*}{$n$} & \multicolumn{2}{|c|}{ Influenza vaccination, $\mathbf{n}(\%)$} \\
\hline & & H1N1 & Seasonal \\
\hline \multicolumn{4}{|l|}{ Patients on immunosuppression } \\
\hline No other risk factor + IS & 134 & $48(35.8)$ & $23(17.2)$ \\
\hline \multirow[t]{2}{*}{ Risk factor + IS } & 24 & $15(62.5)$ & $6(25.0)$ \\
\hline & & $P=0.022$ & $P=0.392$ \\
\hline \multicolumn{4}{|c|}{ Patients without comorbidities meriting vaccination } \\
\hline No other risk factor + IS & 134 & $48(35.8)$ & $23(17.2)$ \\
\hline \multirow[t]{2}{*}{ No other risk factor + no IS } & 75 & $31(41.3)$ & $23(30.7)$ \\
\hline & & $P=0.46$ & $P=0.036$ \\
\hline \multicolumn{4}{|c|}{ Patients with primary care follow-up } \\
\hline$\geq 1$ visit(s) per year & 210 & $96(45.7)$ & $57(27.1)$ \\
\hline \multirow[t]{2}{*}{$<1$ visits per year or no $\mathrm{PCP}$} & 40 & $8(20)$ & $5(12.5)$ \\
\hline & & $P=0.0027$ & $\mathrm{P}=0.071$ \\
\hline
\end{tabular}

IS Immune-suppressive medications; PCP Primary care physician

\section{Statistical analysis}

Frequencies were compared using Fisher's exact test. To assess the strength of the associations while controlling for possible confounding variables, a Cox proportional hazards regression model was used. All baseline variables suspected to impact vaccination status (age $>65$ years, IS use, other indications for vaccination, sex and regular follow-up with a primary care physician) were entered into the model. Results of the analysis are presented as ORs with 95\% CIs. Statistical analysis was performed using GraphPad Prism version 5.03 (GraphPad, USA).

\section{RESULTS}

Characteristics of the 250 subjects are summarized in Table 1 . The age range was 17 to 86 years, with a mean age of 38.6 years. Most participants were female and $70.8 \%$ had Crohn disease. Of the 250 subjects, $104(41.6 \%)$ had been immunized against H1N1 and $62(24.8 \%)$ against seasonal influenza. Use of IS was reported by 158 subjects (63.2\%). The most common IS was azathioprine (83 subjects). In total, 41 subjects $(16.4 \%)$ had additional indications for vaccination (chronic cardiac, pulmonary or renal disease, diabetes mellitus, cancer, pregnancy or age $>65$ years), of whom 24 were also on IS. Age was the most common additional indication, with 18 subjects $>65$ years of age.

The frequency of vaccination among immune-suppressed and nonimmune-suppressed patients with and without additional indications for vaccination are shown in Table 2. Among 209 patients without additional comorbidities warranting vaccination, IS was associated with decreased uptake of vaccination against seasonal influenza (17.2\% versus $30.7 \%$; $\mathrm{P}=0.036$ ) but not $\mathrm{H} 1 \mathrm{~N} 1$ (35.8\% versus $41.3 \%$; $\mathrm{P}=0.46$ ). Among 158 subjects on IS, the presence of comorbidities warranting vaccination was associated with higher likelihood of H1N1

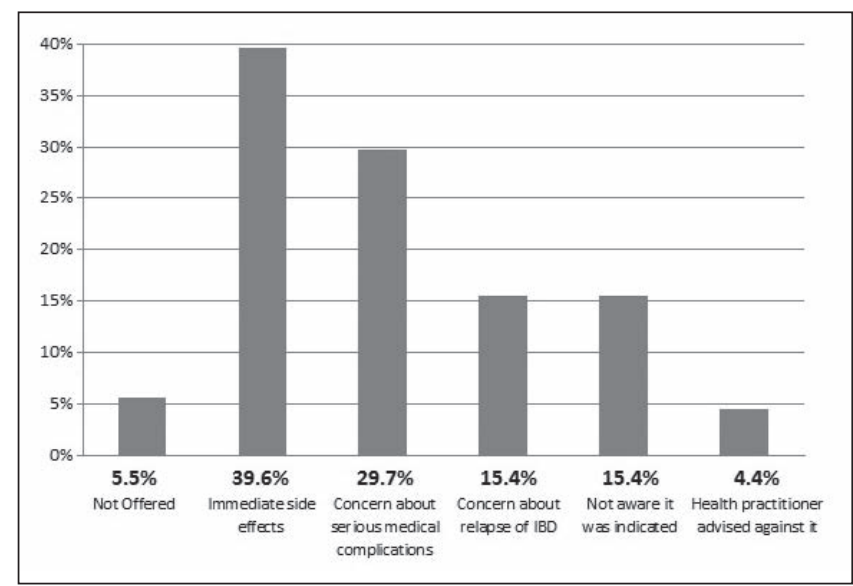

Figure 1) Motive for vaccination refusal by patients using immune suppressing therapies. IBD Inflammatory bowel disease

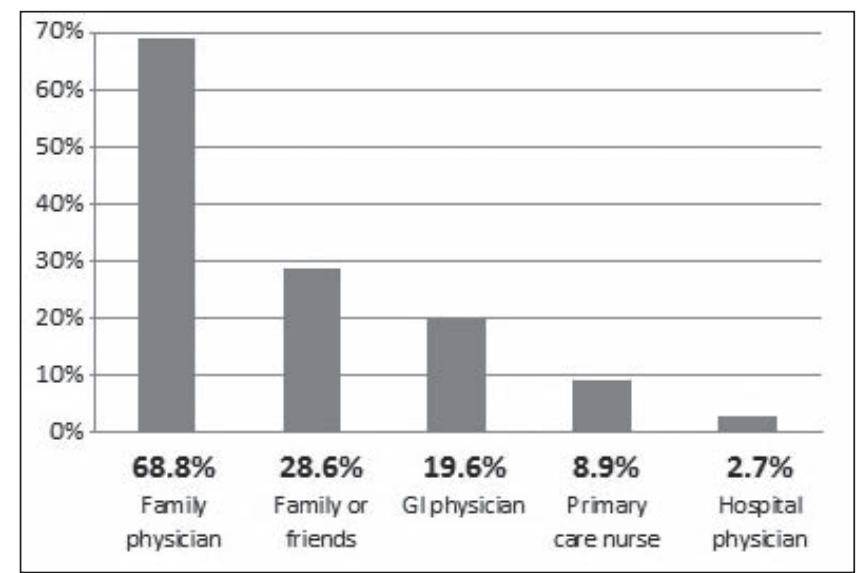

Figure 2) Primary counsel for those vaccinated against H1N1, seasonal influenza or both. GI Gastrointestinal

immunization $(62.5 \%$ versus $35.8 \% ; \mathrm{P}=0.022)$ but not seasonal influenza vaccination $(25.0 \%$ versus $17.2 \% ; \mathrm{P}=0.392)$. The frequency of H1N1 vaccination was significantly higher among patients who visited a general practitioner at least once yearly (45.7\% versus $20 \%$; $\mathrm{P}=0.0027)$, with a similar trend for seasonal influenza vaccination ( $27.1 \%$ versus $12.5 \% ; \mathrm{P}=0.073)$ compared with patients who visited a general practioner less frequently or not at all.

Influenza vaccination had been declined by 91 patients on IS (Figure 1). Of these, 36 (39.6\%) reported fear of immediate side effects and $27(29.7 \%)$ reported concerns about medical complications of vaccination. A smaller number of patients (15.4\%) reported concerns about vaccination leading to relapse of IBD. Importantly, four subjects $(4.4 \%)$ were advised against vaccination by a health practitioner.

Figure 2 reports the sources of counsel for patients who received vaccination against $\mathrm{H} 1 \mathrm{~N} 1$ and/or seasonal influenza. The majority (68.8\%) had been advised by their family physician. Family and friends had influenced $28.6 \%$ of patients. Only a small number of patients were advised by their gastroenterologist (19.6\%) or hospital physician $(2.7 \%)$ to undergo vaccination.

Factors associated with immunization against influenza were assessed by multiple logistic regression analysis (Figures 3 and 4). For H1N1 vaccination, follow-up with a family physician at least once yearly (OR 2.94 [95\% CI 1.26 to 6.83]) was the only significant independent factor, with a trend observed for the presence of a comorbidity indicating vaccination (OR 2.23 [95\% CI 0.95 to 5.22]). For seasonal influenza, IS use was associated with reduced likelihood of vaccination (OR 0.41 [95\% CI 0.22 to 0.74$]$ ) while age $>65$ years was 


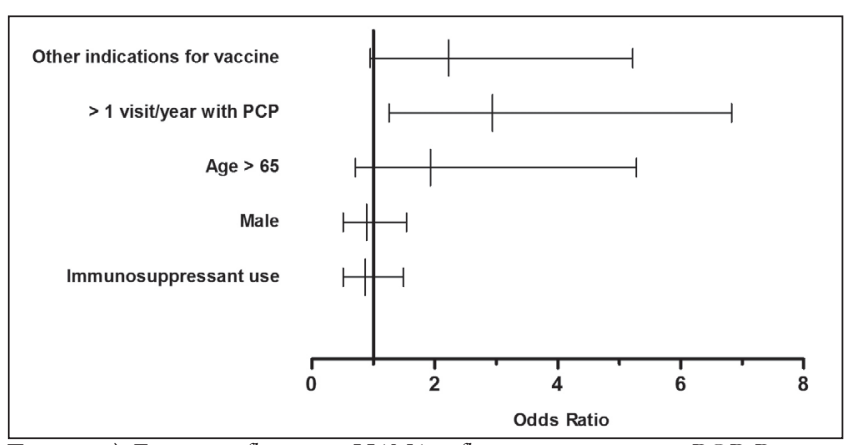

Figure 3) Factors influencing H1N1 influenza vaccination. PCP Primary care physician

associated with a trend toward increased uptake of vaccination (OR 2.28 [95\% CI 0.82 to 6.32$]$ ).

\section{DISCUSSION}

An understanding of immunization practice in IBD patients is important because individuals on IS are susceptible to vaccine-preventable infections. Our audit revealed that IBD patients on IS are, in fact, receiving vaccination against seasonal influenza less often than those not using these medications, even though patients using IS are at higher risk of infection. Other audits have reported similar observations. Melmed et al (10) reported that only $24 \%$ of IBD patients received regular influenza vaccination despite current or previous use of IS in $86 \%$; lack of awareness was the reason for nonvaccination in $49 \%$. Among rheumatology patients, surveys $(11,12)$ have found that only $53 \%$ to $56 \%$ of patients using IS attending rheumatology clinics had received influenza vaccination, with the most common reason for nonimmunization being "never being offered the vaccine".

These data suggest that both patients and health care providers have concerns about vaccination that lead to poor immunization uptake. The majority of patients in our study who declined vaccination cited adverse reactions as a reason. The most common short-term side effects of inactivated influenza vaccines include arm soreness and redness at the injection site (13). Systemic symptoms, such as fever, arthralgia and malaise, occur less frequently but are more common in individuals exposed to the vaccines for the first time (14). Rahier et al (15) reported that similar local and systemic side effects occurred in a large cohort of immunocompromised IBD patients vaccinated against H1N1 and/or seasonal influenza at the same frequency as immunocompetent individuals. Guillian-Barré Syndrome (GBS) is a rare neurological syndrome that was associated with the 1976 swine influenza vaccine at a rate of one per 100,000 persons vaccinated (13). However, subsequent influenza vaccines have not been found to be associated with GBS, and the Advisory Committee on Immunization Practices has stated that the potential benefits of influenza vaccination in preventing serious illness, hospitalization and death outweigh the possible risk of vaccine-associated GBS (2). However, influenza vaccine should not be given to people with acute febrile illnesses, an anaphylactic reaction to a previous dose or with known immunoglobulin E-mediated hypersensitivity to eggs (7). Apart from these scenarios, the safety of vaccination in immune-suppressed patients is good and the riskbenefit ratio is favourable.

Both health care providers and patients may also have concerns regarding immune reactivity, and $15.4 \%$ of our subjects on IS who declined vaccination reported concern about triggering a relapse of IBD. Physicians have reported similar concerns about vaccination of patients with other autoimmune conditions (16). Two case reports have described exacerbation of IBD after vaccination $(17,18)$. However, three studies have shown no increase of disease activity in pediatric and adult IBD patients following the administration of inactivated H1N1 and/or trivalent influenza vaccine $(15,19,20)$. Several larger studies involving other autoimmune conditions have reported adequate humoral responses to vaccination without clinical

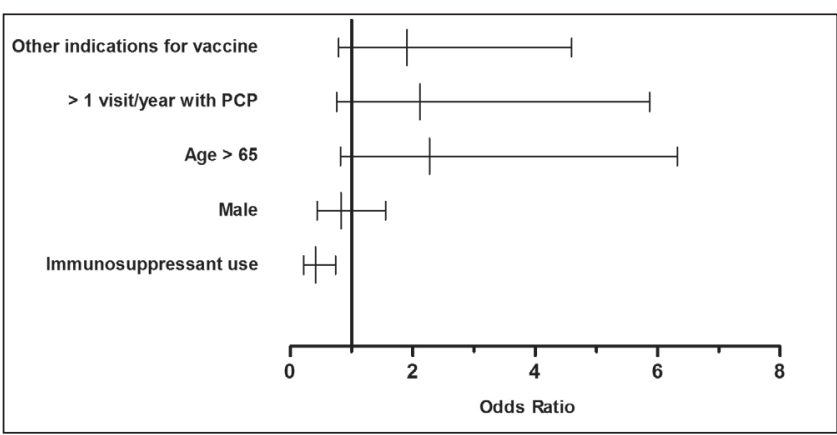

Figure 4) Factors influencing seasonal influenza vaccination. PCP Primary care physician

or biochemical disease reactivation (21-23). Many transplant recipients are not adequately immunized due to concerns about an allograft rejection, even though most studies have failed to demonstrate an association between influenza vaccination and graft rejection (24-26). Patients who express concern about disease reactivation should be counselled about the rarity of such events and the clear health benefits of vaccination.

The majority of patients who received vaccination were counselled to do so by their family physician. In the case of H1N1 influenza vaccination, follow-up with a family physician at least once yearly (OR 2.94 [95\% CI 1.26 to 6.83]) was a significant predictor for immunization. Increasing patients' contact with their family physicians is one way to increase influenza vaccination uptake. All patients, including those without adequate primary care, should also be counselled about vaccination by their gastroenterologist. Gastroenterologists should also collaborate with primary health care providers before each immunization campaign to ensure vaccination of patients on IS. In the present cohort, there was a trend toward higher uptake of seasonal influenza vaccination among individuals $\geq 65$ years of age. This may reflect reimbursement plans in Ontario that reward family health teams for comprehensive vaccination of senior citizens (27). Similar incentives for vaccination of patients using IS should be considered.

Limitations of our study include its moderate sample size and use of a single centre to recruit patients. The results obtained reflect the vaccination status of a referral population, which may not reflect the true immunization state among IBD patients using IS who are followed by a primary care physician. In addition, vaccination status was obtained by self-report, which is subject to recall bias and may not be as accurate as the use of serum titres.

\section{CONCLUSIONS}

Patients with IBD using immune-suppressing therapies are not adequately vaccinated against influenza virus. Poor awareness and uncertainties regarding vaccine safety are two factors responsible for this failure. This may have significant consequences for patients using IS who are vulnerable to serious complications from infection. Raising patient awareness is not sufficient to ensure optimal immunization. Collaboration among primary care providers, gastroenterologists and health care policy makers is needed to improve vaccination uptake.

\section{REFERENCES}

1. Thompson W, Shay D, Weintraub E, et al. Mortality associated with influenza and respiratory syncytial virus in the United States. JAMA 2003;289:179-86.

2. Fiore A, Shay D, Broker K, et al. Prevention and control of influenza. Recommendations of the Advisory Committee on Immunization Practices (ACIP). MMWR Recomm Rep 2008;57:1-60.

3. Public Health Agency of Canada. Influenza (October 28, 2010)

< www.phac-aspc.gc.ca/influenza/index-eng.php>

(Accessed December 20, 2010). 
4. Kangro H, Chong S, Hardiman A, et al. A prospective study of viral and mycoplasma infections in chronic inflammatory bowel disease. Gastroenterology 1990;98:549-53.

5. Harper S, Fukuda K, Uyeki T, et al. Prevention and control of influenza: Recommendations of the Advisory Committee on Immunization Practices (ACIP). MMWR Recomm Rep 2004;53:1-40.

6. Sands B, Cuffari C, Katz J, et al. Guidelines for immunizations in patients with inflammatory bowel disease. Inflamm Bowel Dis 2004;10:677-92.

7. Public Health Agency of Canada. Statement on Seasonal Trivalent Inactivated Influenza Vaccine (TIV) for 2010-2011 (August 6, 2010) <www.phac-aspc.gc.ca/publicat/ccdr-rmtc/10vol36/acs-6/ index-eng.php $>$ (Accessed December 20, 2010).

8. Rahier J, Ben-Horin S, Chowen Y, et al. European evidence-based consensus on the prevention, diagnosis and management of opportunistic infections in inflammatory bowel disease. JCC 2009;3:47-91.

9. Narula N, Yamamura D, Marshall J. Should my patient with inflammatory bowel disease on immunosuppressive therapy be vaccinated against influenza virus? Can J Gastroenterol 2010;24:121-5.

10. Melmed G, Ippoliti A, Papadakis K, et al. Patients with inflammatory bowel disease are at risk for vaccine-preventable illnesses. Am J Gastroenterol 2006;101:1834-40.

11. Sowden E, Mitchell W. An audit of influenza and pneumococcal vaccination in rheumatology outpatients. BMC Musculoskelet Disor 2007;8:58.

12. Bridges M, Coady D, Kelly C, et al. Factors influencing uptake of influenza vaccination in patients with rheumatoid arthritis. Ann Rheum Dis 2003;62:685.

13. Bridges C, Thompson W, Meltzer M, et al. Effectiveness and cost-benefit of influenza vaccination of healthy working adults: A randomized controlled trial. JAMA 2000;284:1655-63.

14. Fiore A, Bridges C, Cox N. Seasonal influenza vaccines. Curr Top Microbiol Immunol 2009;333:43-82.

15. Rahier J, Papay P, Salleron J, et al. H1N1 vaccines in a large observational cohort of patients with inflammatory bowel disease treated with immunomodulators and biological therapy. Gut 2011;60:456-62.
16. Holvast B, Huckriede A, Kallenberg C, et al. Influenza vaccination in systemic lupus erythematosus: Safe and protective! Autoimmun Rev 2007;6:300-5.

17. Kwan O, Park Y, Choi J, et al. A case of ulcerative colitis relapsed by influenza vaccination. Korean J Gastroenterol 2007;49:327-30.

18. Fields S, Baiocco P, Korelitz B. Influenza vaccinations: Should they really be encouraged for IBD patients being treated with immunosuppressives? Inflamm Bowel Dis 2009;15:649-51.

19. Lu Y, Jacobson D, Ashworth L, et al. Immune response to influenza vaccine in children with inflammatory bowel disease. Am J Gastroenterol 2009;104:444-53.

20. Mamula P, Markowitz J, Piccoli D, et al. Immune response to influenza vaccine in pediatric patients with inflammatory bowel disease. Clin Gastroenterol Hepatol 2007;5:851-6.

21. Elkayam O. Safety and efficacy of vaccination against influenza in patients with rheumatoid arthritis. Clin Dev Immunol 2006;13:349-51.

22. Oren S, Mandelboim M, Braun-Moscovici Y, et al. Vaccination against influenza in rheumatoid arthritis patients: The effect of rituximab on the humoral response. Ann Rheum Dis 2008;67:937-41.

23. Salemi S, Picchianti-Diamanti A, Germano V, et al. Influenza vaccine administration in rheumatoid arthritis patients under treatment with TNF alpha blockers: Safety and immunogenicity. Clin Immunol 2010;134:113-20.

24. Candon S, Thervet E, Lebon P, et al. Humoral and cellular immune responses after influenza vaccination in kidney transplant recipients. Am J Transplant 2009;9:2346-54.

25. Kobashigawa J, Warner-Stevenson L, Johnson B, et al. Influenza vaccine does not cause rejection after cardiac transplantation. Transplant Proc 1993;25:2738-9.

26. Mauch T, Crouch N, Freese D, et al. Antibody response of pediatric solid organ transplant recipients to immunization against influenza virus. J Pediatr 1995;127:957-60.

27. Ontario Ministry of Health and Long-Term Care. Guide to Physician Compensation. (September 2009) <www.health.gov.on. $\mathrm{ca} /$ transformation/fht/guides/fht_compensation.pdf $>$ (Accessed December 20, 2010). 


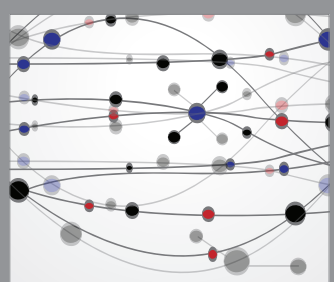

The Scientific World Journal
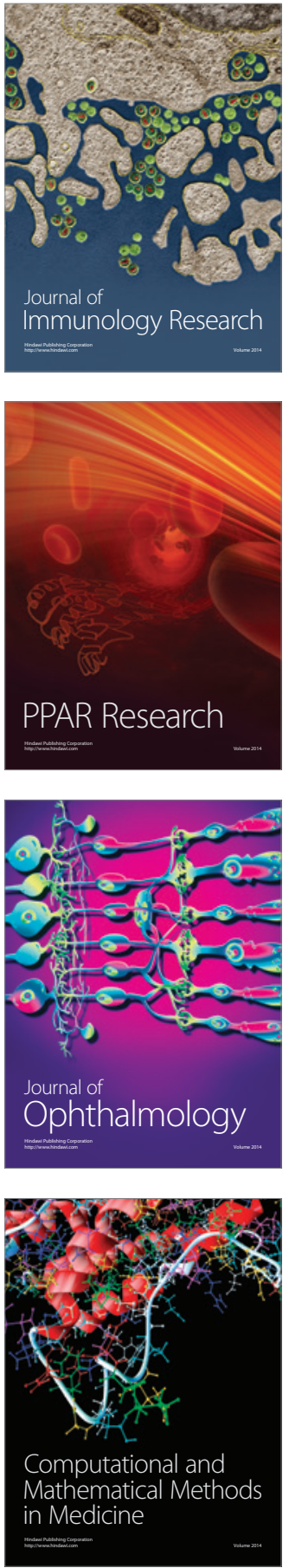

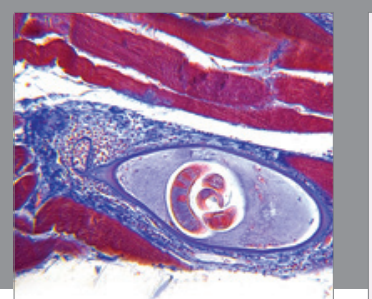

Gastroenterology Research and Practice

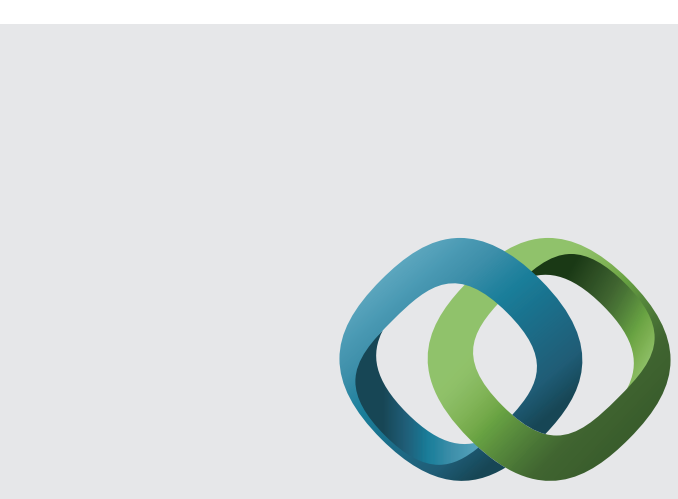

\section{Hindawi}

Submit your manuscripts at

http://www.hindawi.com
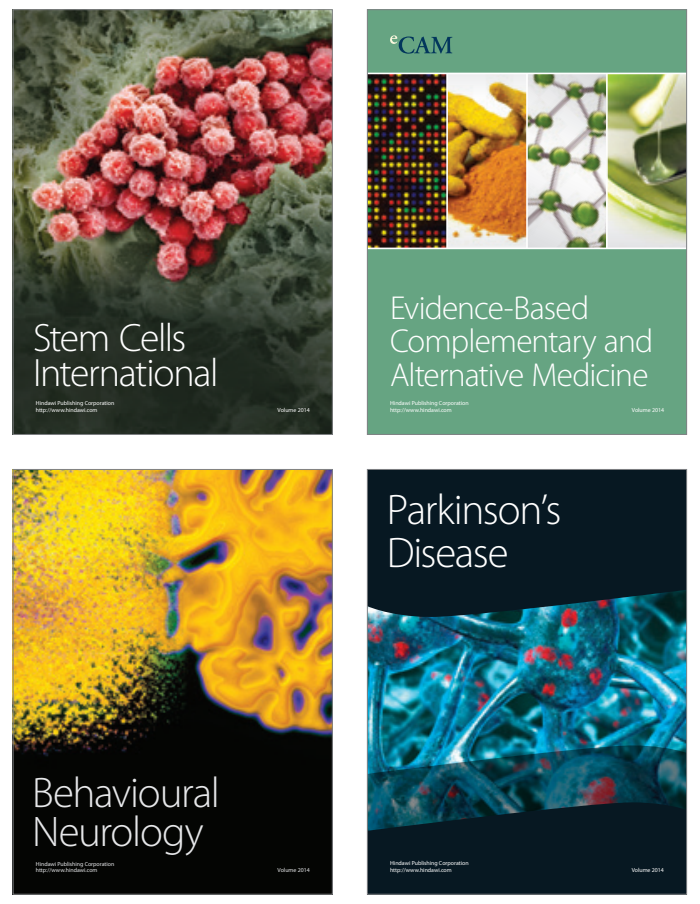
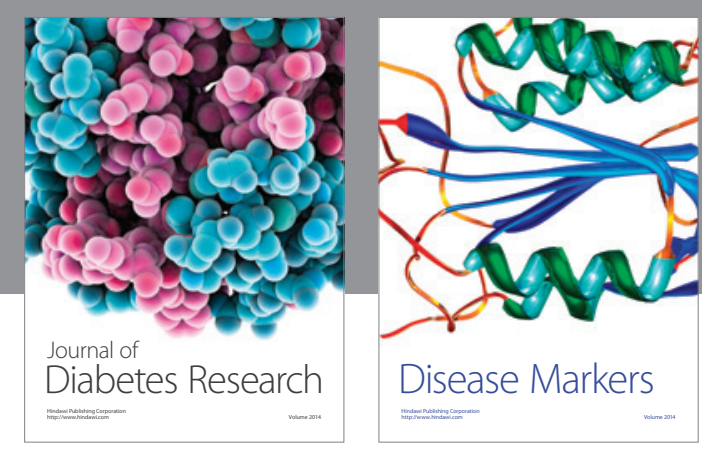

Disease Markers
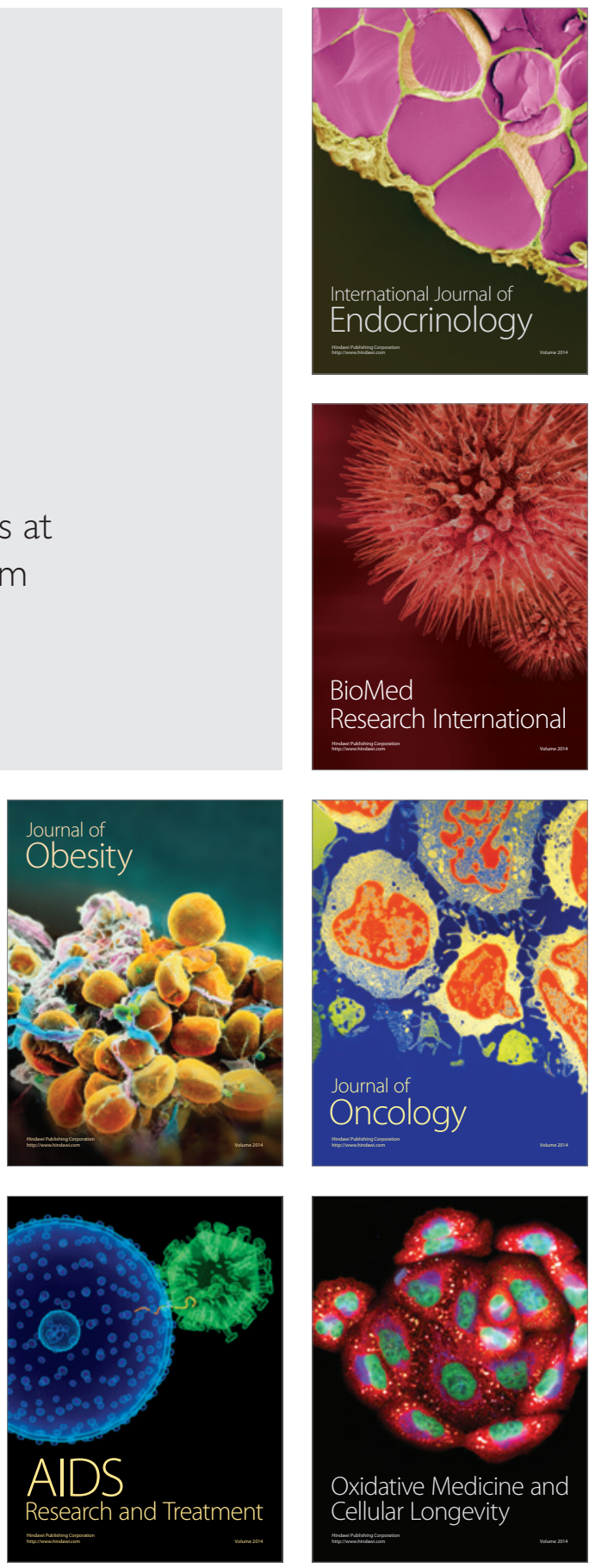